\title{
TECHNOLOGY FOR PRODUCING M1ODM OIL BASED ON OIL DISTILLATES FERGHANA OIL PROCESSING PLANT (FOPP)
}

\author{
Ergashev Mahmudjon Mamadjanovich \\ $\mathrm{PhD}$, \\ Fergana Polytechnic Institute, \\ Fergana city, \\ Uzbekistan.
}

Article DOI: https://doi.org/10.36713/epra2272

\section{ANNOTATION}

A technology for producing M-10 DM engine oil using the K-471 n. additive package has been developed, which provides high performance characteristics.

KEY WORDS: additives, oil, raw materials, additive, resin, phenols.

\section{INTRODUCTION}

The ever-increasing demand for lubricating oils can only be met by expanding their range in accordance with the requirements of the equipment used and the technological capabilities of the oil refining industry. Severe operating conditions of high-powered diesel engines, which are widely distributed in the territory of the Republic of Uzbekistan, impose increased requirements for the quality of engine oil. Oils intended for these purposes must have, first of all, high thermal-oxidative stability, an increased stock of washing-dispersing and anti-carbon properties, as well as long-term anti-wear, anti-corrosion and anti-pressure qualities [1].

\section{OBJECTIVES}

One of the main conditions for the intensification of oil production is the constancy of the composition of oil raw materials with a high content of desirable components. A special feature of the Ferghana refinery is the use of a mixture of local high-sulfur raw materials from the Kokdumalak oil field, Kazakh oil (Kumkol) and gas condensate. The chemical composition of base oils depends on the nature of the raw material and the technological parameters of its processing processes, so a cycle of works was carried out at the FOOP to modernize the oil production without reducing the selection of the target product. In order to select the most rational technology for cleaning oil distillates, which ensures the production of oils with the specified parameters and the maximum yield of the target product, the chemical composition of the raw material and the properties of its individual groups of hydrocarbons, which determine such important performance characteristics of the base oils as viscosity, viscosity index and pour point, are studied in detail.

\section{METHODOLOGY}

It is shown that oil distillates and deasphaltisates obtained at the fnpz, along with high-index low-cyclic naphthenic and aromatic hydrocarbons with a high proportion of short side chains, also contain a significant amount of low-index polycyclic aromatic hydrocarbons, resins, as well as sulfur and nitrogen compounds. Analysis of the components of base oils obtained by selective purification with phenol at the fnpz revealed a significant difference in their properties, which often do not meet the criteria of international standards, according to which the carbon content in aromatic rings should not exceed $7 \%$. In addition, base oils obtained from high-sulfur raw materials of unstable chemical composition often contain an understated number of high-index components and a lot of resins (up to $3.1 \%$ ) [1]. As a result, in order to obtain motor oil of the M-10 DM brand corresponding to GOST, it is necessary to select different fractions of oil distillate obtained during complex processing, including vacuum distillation, selective purification with phenol, dewaxing and Hydrotreating. The optimal ratio of the base components was found experimentally, providing the base oil viscosity at $100^{\circ} \mathrm{C}$ within $7.5-8.5 \mathrm{cSt}$ : the III fraction is $45 \%$ and the remainder is $55 \%$. Table- 1 .

\section{STATISTICAL DESIGN}

Characteristics of the initial components and $10 \mathrm{DM}$ oil based on them table-1 


\begin{tabular}{|c|c|c|c|c|c|c|}
\hline \multirow{3}{*}{$\begin{array}{l}\text { Indicators } \\
\text { Kinematic viscosity, } \mathrm{MM}^{2} / \mathrm{c} \text {, at } 100^{\circ} \mathrm{C}\end{array}$} & \multicolumn{2}{|c|}{ Components of the base oil - } & \multicolumn{4}{|c|}{ OIL $10 \mathrm{DM}$} \\
\hline & \multirow{2}{*}{\begin{tabular}{|r|} 
III fraction \\
$6,8-7,8$
\end{tabular}} & \multirow{2}{*}{\begin{tabular}{|r|} 
Residual \\
$19,45-20,82$
\end{tabular}} & \multicolumn{3}{|l|}{ Actual } & \multirow{2}{*}{$\begin{array}{l}\text { GOST } \\
\geq 11,4\end{array}$} \\
\hline & & & 11,96 & 11,77 & 11,82 & \\
\hline Viscosity index & $96-102$ & $94-95$ & 97 & 96 & 100 & 96 \\
\hline The density at $20^{\circ} \mathrm{C}, к г / д м^{3}$ & $0,885-0,887$ & $0,902-0,904$ & 0,902 & 0,895 & 0,900 & 0,905 \\
\hline Base number, мг КОН /г & & & 8,32 & 8,25 & 8,34 & $\geq 8,2$ \\
\hline $\begin{array}{l}\text { Color on the colorimeter CNT, unit CNT } \\
\text { with dilution } 15: 85 \text {, at CNT }\end{array}$ & $2,7-2,9$ & $6,0-6,2$ & 2,5 & 3,5 & 3,7 & $\leq 3,5$ \\
\hline $\begin{array}{l}\text { Flash point, }{ }^{\circ} \mathrm{C} \\
-\quad \text { in an open crucible } \\
-\quad \text { closed crucible }\end{array}$ & $210-230$ & $200-260$ & 224 & 232 & 244 & $\geq 220$ \\
\hline Pour temrature, ${ }^{\circ} \mathrm{C}$ & -15 & -15 & -18 & -18 & -18 & $\geq-18$ \\
\hline $\begin{array}{l}\text { Mass fraction of mechanical impurities, } \\
\%\end{array}$ & 0,0047 & 0,0048 & 0,010 & 0,015 & 0,017 & $\leq 0,025$ \\
\hline Sulphate ash content, \% & & & 0,68 & 0,71 & 0,83 & $\leq 1,5$ \\
\hline $\begin{array}{l}\text { Mass fraction of active elements: } \\
\text { calcium } \\
- \text { zinc }\end{array}$ & & & $\begin{array}{c}0,35 \\
0,097\end{array}$ & $\begin{array}{c}0,32 \\
0,093\end{array}$ & $\begin{array}{c}0,37 \\
0,098\end{array}$ & $\begin{array}{l}\geq 0,03 \\
\geq 0,09\end{array}$ \\
\hline Corrosion on the plates of lead, $\Gamma / \mathrm{M}^{2}$ & & & & Absent & & At. \\
\hline $\begin{array}{l}\text { Stability over the induction period of } \\
\text { sedimentation (NGO) }\end{array}$ & & & & ithstands & & $\geq 60$ \\
\hline
\end{tabular}

However, the complex of additives usually used to produce motor oil of the M-10 DM type proved to be insufficiently effective when injected into the resulting base oil. Therefore, employees of the Federal customs service, together with the scientific and production enterprise "Quality", conducted a study to select the composition of additives for oil type M-10 DM, providing a high level of motor performance properties. The compounding series of prototypes distillates with different color characterizing the degree of purification, showed that the required level of quality end product is achieved only by using well-purified base oil, the optimum chemical composition and balanced composition of additives of polyfunctional action K-471 (table-1). 


\section{RESULTS}

The alkaline number is one of the most important indicators of the neutralizing ability of oils, in addition, it directly or indirectly characterizes the level of performance and performance of motor oils. Sulfonates of alkaline earth metals are widely used as detergentdispersing additives to motor oils in order to increase the alkaline number. In [2-3], it is shown that mediumalkaline additives based on alkylphenol formaldehyde condensation products are equally effective in improving the cleaning and antioxidant properties of the oil, as well as significantly reducing the tendency to varnish formation at high temperature. The effectiveness of these additives is significantly affected by the nature of the cation in their structure. For example, in terms of dispersing and anticorrosive efficiency, calcium sulfonate is somewhat superior to the corresponding barium and strontium sulfonates, but the most toxic barium sulfonate shows the greatest effect in increasing thermal stability [2]. In addition, sulfonates of alkaline earth metals, with a General reduction in the content of additives in the composition, provide high physical, chemical and functional properties.

\section{SUGGESTIONS}

As a result of the conducted experiments, it was found that this base oil shows the greatest pick-up in relation to the package of $\mathrm{K}-471 \mathrm{n}$ additives produced by JV Pharma. In addition to neutral, medium-alkaline and 'high-alkaline calcium sulfonates, the package also includes alkylphenol and succinimide additives, as well as high-temperature antioxidant additive $\mathrm{K}-34$ and additive A-22. The optimal concentration (4-6\%) of the additive $\mathrm{K}-471 \mathrm{~h}$ was found. Heavy operating conditions for the engines of quarry heavy-duty dump trucks, excavators, and similar equipment for which the M-10 DM oil is intended require increased depressor properties. This effect is achieved by the additional introduction of a special additive K-110 that modifies the crystal structure of solid hydrocarbons while maintaining the mobility of the oil at relatively low temperatures. Since many of the chemicals introduced into the base oil have foaming properties, the use of an anti - foam additivepolymethylsiloxane-is provided for accelerated foam destruction.[4] for the production of M-10DM oil, the Technological regulations and Technical conditions have been developed.

\section{CONCLUSION}

Thus, the use of the K-471 $\mathrm{n}$ additive package in combination with the K-110 depressor additive made it possible to obtain a motor oil with high functional properties that fully complies with GOST 8581. Due to good quality, m10dm engine oil is widely used by enterprises of the Republic of Uzbekistan and is imported to the CIS and foreign countries.

\section{REFERENCES}

1. Sochevko T. I., Pakhomov M. D., Falkovich M. I., Yevtushenko V. M. Of base and commercial oils. // Chemistry and technology of fuels and oils, 2000, no. 2, Pp. 37-39.

2. Sadykhov K. I., Agaev A. N., Velieva S. M. medium-Alkaline sulfonate additive to motor oils. // Chemistry and technology of fuels and oils, 2001, no. 1, Pp. 27-28.

3. Lashhi V. L., Leimeter T, Shor G. I., Falkovich M. I. Alkaline number as an indicator of compatibility of additives to engine oil. // Chemistry and technology of fuels and oils, 2001, no. 5, Pp. 49-51.

4. Abdullayev Ibrohim Numanovich, Marupov Azizxon Abbosxonovich, "THE ANALYSIS OF LANDS IN SECURITY ZONES OF HIGH-VOLTAGE POWER LINES (POWER LINE) ON THE EXAMPLE OF THE FERGANA REGION”, 2020, №2, doi: 10.36713/EPRA3977 